\title{
Theory of analysis of the innovative ecosystems development
}

\author{
Evgeny Popov*, Victoria Simonova, and Igor Chelak \\ ${ }^{1}$ Ural Institute of Management - a branch of the RANEPA, 66, 8 Marta Str., Yekaterinburg, 620144, Russian Federation
}

\begin{abstract}
The ecosystem approach makes a significant contribution to understanding the current transformations of socio-economic life. New end-to-end technologies have a high potential to minimize the transaction sector in order to focus on meeting the real needs of people and firms and forming economic, political, cultural, and value institutions for sustainable development and justice for all. It seems that the technological breakthroughs of recent years, as well as the reverse pandemic economic dynamics, provide ample opportunities for the spread of innovative ecosystems as a new form of coordination of production activities. The unique characteristics of ecosystems as predominantly self-organizing communities allow us to identify a number of conceptual approaches to the analysis of their development: network, system, digital, stakeholder, and transactional. The objectives of the article do not include their detailed presentation. We show the applicability of approaches for ecosystem analysis. Based on the description of the options and possibilities for the applicability of these approaches, we came to the conclusion that the nature of innovative ecosystems is dual. First, the latter allow us to model (structure, systematize) interorganizational, inter-firm relations in a new way, to identify ecosystem features of communities, industrial and regional complexes. Second, ecosystems need to be recognized as a new form of transactional coordination of economic activity. They are alternatives to institutions such as the firm, the market, and hybrid forms. The increment of scientific knowledge consists in the implementation of the main goal of the study - the systematization of methods for analyzing the development of innovative ecosystems based on the formation of ideas for ecosystem analysis of innovation management.
\end{abstract}

\section{Introduction}

Digitalization, networking of business and social life have become the dominant trends in the development of both the service and commodity economy over the past decade. And in 2020, perhaps the most "destructive innovation" in history appeared-a total lockdown. The current epidemiological situation is turning the world economy into a reverse one. The waves of the pandemic directly affect the growth and slowdown of production, entrepreneurial and innovative activity and consumption, migration from the offline environment of activity to online and back. Unstable, turbulent conditions require economic agents to be flexible, adaptable, and quickly change the types of transactions. Such advantages are provided by ecosystems that allow you to build business models outside of rigid frameworks, hierarchical coercion, clear boundaries, in some cases - without contractual registration of relations.

The scientific ideas that were at the origin of the application of the ecosystem approach were more inclined to use analogies with natural self-organizing ecosystems in economic analysis than modern publications. Among the latter, there are studies aimed at finding methods for managing ecosystems as a response to the risks of their possible unpredictable development trajectories $[1,2]$. It is worth recalling that one of the program articles of James Moore, who introduced the concept of ecosystems into economic terminology, is called "Predators and prey: The new ecology of competition" [3]. It is noteworthy that the main economic concepts: development, growth, are also introduced from the natural sciences. Interdisciplinarity allows us to take a fresh look at economic phenomena. Perhaps in the future, the economy will be considered exclusively from the point of view of the interaction of ecosystems as a concept that most fully reflects the relationship between economic entities and environmental factors [4].

A number of authors do not share the optimism about the possibility of shifting the focus of economic analysis mainly to the ecosystem approach. L. Ramenskaya points out that the use of the prefix "eco", in particular, in the analysis of innovative systems, is not always justified [5].

The ecosystem research paradigm expands the traditional understanding of economic relations as an interaction of independent actors. The essence of the concept of innovative ecosystems (IES) is the position that all actors within conditional territorial boundaries are somehow interconnected [3, 6], through strong and weak, implicit interactions (by analogy with the physical nature of objects in the Universe).

* Corresponding author: chelak@mail.ru 
On the other hand, the authors of newly emerging economic models and concepts are forced to respond to the rapid platformization and centripetal ecosystem processes occurring in the business environment, and to include ecosystem concepts in the arsenal. Thus, D. Bryukhanov and co-authors, analyzing the popular EFQM model, point out that "in contrast to the traditional concept of a competitive environment, [in the EFQM model] the economic activity of an organization is considered as an ecosystem, which includes consumers and producers, partners and competitors, and other interested parties" [7].

An important aspect of the nature of the socioeconomic ecosystem, in contrast to the company as an artificially created (artificial) system, is mainly independent generation, self-organization, selfdevelopment [8]. Inversive relationships [9] in the ecosystem and hybrid forms of coordination arise spontaneously, not hierarchically, and in this way there is a certain similarity with the market. But an ecosystem is not a spontaneous market or a particular case of a hybrid. It is more a cognitive analysis tool than a management tool. Given the enormous potential of ecosystems to reduce transaction costs in modern conditions [10], we will later discuss in more detail the hypothesis of the place of ecosystems in the set of forms of economic coordination.

\section{Features of innovative ecosystems}

From a number of ecosystem paradigms, we will distinguish two concepts of understanding the innovation ecosystems. The first is based on the recognition of any business activity (and the ecosystem in which the activity is carried out) as innovative: set up for renewal, innovation, constant changes in all areas of production activity [11]. This approach is closer to the Schumpeterian understanding of innovation as the basis of entrepreneurship [12]. The second concept focuses on a relatively narrow understanding of innovation, and considers the innovation ecosystem as a condition for the development and commercialization of innovations as new products and services, "new value propositions" [1]. This approach focuses on research and marketing activities, development institutions, and the infrastructure of innovative ecosystems. In general, these paradigms do not contradict each other and can be considered as a partnership. But despite the variety of approaches to understanding the phenomenon under consideration, there is a lack of systematization of approaches to the analysis of the innovative ecosystems development in existing studies. And this is quite understandable from the perspective of the formation of an ecosystem paradigm that has every chance to become a new theory of ecosystems, along with such wellestablished systems of scientific knowledge as the theory of the firm or the theory of markets. Hence, the purpose of this study is to contribute to the developing theory of ecosystems by systematizing methods for analyzing the innovative ecosystems development based on the formation of ideas for ecosystem analysis of innovation management.

\section{Materials and methods}

Applying the concept of innovative ecosystems, researchers focus on the conditions, interaction factors, focused on the creation of novelty. Logical, structural, and systematic methods are the starting methods for studying the development of ecosystem analysis of innovation process management. Complements the set of analysis of scientific publications. The research materials are scientific developments concerning the relationship between economic entities - stakeholders of ecosystems: firms, households, the state and other structural elements of the socio-economic environment. The paradigmatic basis of the research was system theory, institutional theory, concepts of network interaction and stakeholder relations, as well as a new type of economic interaction digital (Econotronics).

\section{Results}

Table 1 shows the main methods of ecosystem analysis that allow us to collectively consider the most significant parameters of innovative ecosystems.

Table 1. Methods of ecosystem analysis

\begin{tabular}{|c|c|}
\hline $\begin{array}{l}\text { Methods of analysis } \\
\text { and sources of the } \\
\text { theory of analysis of } \\
\text { the development of } \\
\text { innovative ecosystems }\end{array}$ & $\begin{array}{l}\text { Fundamentals of the analysis of } \\
\text { the development of innovative } \\
\text { ecosystems }\end{array}$ \\
\hline $\begin{array}{l}\text { Network potential } \\
\text { theory [13] [14] }\end{array}$ & $\begin{array}{l}\text { The presence and characteristics } \\
\text { of links between the elements of } \\
\text { the ecosystem can be assessed } \\
\text { through the network potential of } \\
\text { the elements (firms, } \\
\text { organizations, communities) }\end{array}$ \\
\hline System theory [15] [4] & $\begin{array}{l}\text { The analysis of ecosystems is } \\
\text { based on the discreteness/ } \\
\text { continuity of space and time }\end{array}$ \\
\hline $\begin{array}{l}\text { Theory of stakeholder } \\
\text { interaction [16] }\end{array}$ & $\begin{array}{l}\text { Ecosystem analysis is carried out } \\
\text { by identifying the pool of } \\
\text { ecosystem stakeholders and } \\
\text { assessing their mutual influence }\end{array}$ \\
\hline $\begin{array}{l}\text { Digital Potential theory } \\
{[17]}\end{array}$ & $\begin{array}{l}\text { The analysis is carried out by } \\
\text { assessing the digitalization of } \\
\text { inter-organizational interactions } \\
\text { in the ecosystem }\end{array}$ \\
\hline $\begin{array}{c}\text { Transactional } \\
\text { configuration theory } \\
{[18][19][21]}\end{array}$ & $\begin{array}{l}\text { The analysis can be carried out by } \\
\text { the ratio of asset specificity and } \\
\text { transaction costs, since, on the } \\
\text { one hand, ecosystems occupy an } \\
\text { intermediate position between } \\
\text { hybrids and the market, on the } \\
\text { other hand, they can be } \\
\text { distinguished as a separate form } \\
\text { of coordination }\end{array}$ \\
\hline
\end{tabular}

Source: author's development 


\section{Discussions}

Network theory (the concept of network readiness) is primarily aimed at analyzing the potential for convergence, integration, and permanent communication of the entrepreneurial core of the innovation ecosystem (firm) with partners of the same order. Graphically, the network effect of inter-firm interactions manifests itself on the plane, in the structures of non-hierarchical configurations. The formation of partnerships in graphs strengthens the innovative potential of the network, and the inclusion of the interaction environment in the objects of analysis forms the vision of the network ecosystem. Research in one of the most" breakthrough " industries in the modern economy (the information technology sector [14]) has shown that networking can generate significant innovative effects. This approach has the potential to develop in the context of the information society evolution, based on the fact that information is an essential resource, especially from a behavioral and psychological point of view (in particular, to overcome negative institutional effects reducing distrust, eliminating information asymmetry).

Of course, the analytical concepts presented here work in practice in conjunction with other paradigms. Thus, the network potential shows the dynamic, structural aspect of ecosystem interactions, one of the priority goals of which is to reduce transaction costs, and in this regard, the network approach brings us closer to the scheme of Oliver Williamson (Figure 1), where the network as a mechanism of economic coordination is a pure hybrid, combining both market and firms forms of contracting.

The systematic approach to the analysis of innovative ecosystems, developed in the research of G.B. Kleiner and his colleagues, is characterized by a broad historical scientific and methodological base, which allows us to consider the spatial evolution of socio-economic ecosystems as dynamic, open communities. It should be noted that the ecosystem theory itself was originally formed due to the theory of systems [20]. Laid down in the basis of the author's systematic approach Kleiner's universal concept of "space-time" introduced fundamental physical phenomena into economic research that allow us to study innovation ecosystems from the point of view of "intra - and intersystem, horizontal and vertical, interperiodic and interzonal coordination of innovation participants" [15]. The system approach suggests considering ecosystems from the perspective of a tetrahedron: objects-environmentprocesses-projects, deployed in specific communities clusters, platforms, networks, incubators. Thus, the network concept also finds its application in the analysis methodology under consideration.

The stakeholder approach is characterized by increased attention to the conditionally external environment of economic activity, which accelerates and intensifies the generation of innovations (due to the presence of dense, strong or implicit, weak links with various elements of the environment). The approach allows to eliminate inefficient attitude to stakeholders as to the periphery of business processes. On the contrary, the novelty of the ecosystem paradigm is to emphasize the conceptual role of the environment of the central element of the ecosystem (for example, firms, platforms, communities). Consumers, competitors, suppliers, government authorities, socio-political institutions, mass media and social media, the scientific and educational sector, and infrastructure organizations play the most prominent role in the environment. The function of equal participants of the ecosystem is postulated for the stakeholders. Without them, it is difficult to explain the nature of the innovative effects of the company's activities. Within the framework of the concept of mutual influence of stakeholders on each other, the nature of self-organization, self-development of the innovation ecosystem can be explained, as well as its capacity can be calculated. The power of the IES is manifested in two ways. The element capacity depends on the typology of stakeholders, their number, and the prevailing transactions. Innovation power describes the ability of an ecosystem to produce and distribute productive innovations.

The emerging transformation of the post-industrial information economy into a digital one leads to the need to develop up-to-date research algorithms. The theory of digital potential can be fruitful in the study of ecosystems due to the fact that the rapid formation of the latter in recent years is due to significant technological progress and economic potential (especially in terms of cost reduction) of information and communication technologies, which is clearly shown by the examples of the largest players in the digital economy, whose ecosystems were formed from seemingly ordinary applications: local social networks (Facebook), search services (Google), online stores (Amazon, AliExpress). Digital business models in the presence of competent management, marketing, and not yet detectable the energy of ecosystem self-organization are able to combine sources of added value, consumers (no matter what-goods, services, content), other stakeholders, groups of influence in a virtual form, but real in economic effects configuration.

Digitalization is not limited to automation and a focus on big data. This is where the deployment chain of most end-to-end technologies develops. For example, Big data analysis requires conditions for automatic data collection, machine vision, artificial intelligence, distributed ledgers (blockchain) for data transfer and protection, cloud technologies for storage, advanced communication systems and Internet communications, digital media for collecting feedback and reflection. Of course, the availability of technological capabilities is not the determining and only condition for the platform growth of the innovation ecosystem. For consumers, the economic opportunities that modern platforms provide are valuable. The hype effect and the search for factors that influence the rapid growth of the popularity of individual ecosystems are also highly important (for example, where is Facebook and its main competitor in the 2000s, MySpace?).

The digital approach to ecosystem analysis makes it possible to adjust management strategies, evolve marketing techniques, and prepare for new technological 
perspectives (it is difficult to imagine how a quantum computer will change the digital and real world).

The institutional design of coordination in economic activity is determined by the ratio of benefits and losses from the corresponding configuration of transactions. To determine the subject of the transactional approach to the innovation ecosystem, the concepts of transaction costs and asset specificity are introduced into the analysis tools.

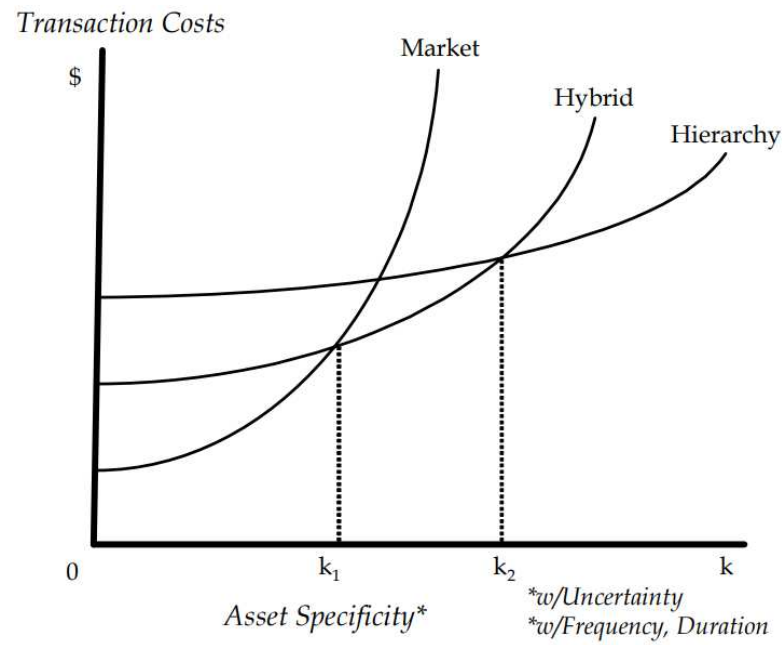

Figure 1. Transaction configuration forms Source: [18]

Ecosystems, along with other forms of collective activity, decide on the effective use of resources and the rules for this kind of activity. Markets, firms - wellestablished institutions in the economy. In contrast, ecosystems have not yet received an unambiguous interpretation, including an institutional one. Where is the basis here? What type of contract between stakeholders prevails? Starting from the theory of Oliver Williamson, we propose to consider the forms of coordination broadly, including in the sphere of analysis both the core of innovative ecosystems (firms) and the elements of the environment in which they operate, the environment itself. Therefore, a cluster, alliance, partnership, or network (forms that do not claim to include the environmental component within their boundaries) can be classified as hybrid forms of coordination as synthetic configurations that combine the characteristics of a market and a firm, and ecosystems can be separated into a unique class. On the other hand, if the firms configurations of economic activity clearly gets the characteristics of the ecosystem due to the effect of minimizing transaction costs and reducing the risk of depreciation of specific assets, which is clearly manifested in platform digital ecosystems, is it methodologically correct to classify it as a firm or ecosystem? From a practical point of view, the application of the institutional approach allows us to solve the issues of minimizing the transaction costs of choosing and configuring institutions. But in the real conditions of economic life, modern forms and models of global corporations are difficult to assess from the point of view of the classical "firm - market" scheme. What, for example, is a platform like Alibaba? To what configuration is it appropriate to refer the SBER system, which includes completely different sectors of the economy and business models?

From the point of view of the number of subjects of management of forms of transactions, the ecosystem can be considered hybrid, because here, unlike the market, there can not be an unlimited number of subjects of management and, unlike the firm, there can not be a single dominant. From the point of view of the frequency of transactions, the ecosystem is located on the border of constantly occurring and rarely occurring transactions. As a result, it is possible to determine the place of the ecosystem in the scheme of forms of coordination of economic activity only after the fundamental establishment of the nature of the ecosystem itself, its essential features. If the ecosystem is understood as a certain community of stakeholders, in the center of which the analyzed firm, enterprise, company is a hybrid with a set of management subjects more than one. If an ecosystem is interpreted as an environment of interactions, institutions, and infrastructure components (for example, a regional innovation ecosystem), then Oliver Williamson's three-tier set of alternatives is not fully applicable, and the ecosystem has a higher-order configuration than a hybrid. With this understanding, we can state the need to supplement the set of alternatives for the transactional configuration with this large fourth element.

\section{Conclusions}

Scientific research and business practice, including social entrepreneurship, indicate a high potential for the development of innovative ecosystems in the near future (both regional ones, where the authorities are the conditional center of orchestration, and entrepreneurial ones).

The new leaders of the economy are ecosystems. Examples are the most expensive corporationsMicrosoft, Apple, Amazon, Alphabet (Google), Alibaba, Facebook. And these examples inspire other companies to transform and become ecosystems. In Russia, the flagships of ecosystem evolution are SBER and Yandex. Enterprises of ROSTEC, ROSCOSMOS, and ROSATOM corporations are showing interest in ecosystems. The ecosystem approach in the near future has every chance to change the concept of the company as the main business configuration.

These approaches allow both individually and jointly (systemically) to provide researchers with a variety of tools for analyzing the development of innovative ecosystems.

The ecosystem approach has a characteristic feature, in contrast to the concepts where the company is at the center of the analysis and the achievement of outstanding performance primarily depends on this company, the main methods of analysis are concentrated on it. The emphasis in the ecosystem is shifting to the formation and development of interactions, connections of elements, transactions of stakeholders, and "background" environmental influence. 
The methods of the theory of ecosystem analysis are applicable for:

- mapping, institutional and structural design of the ecosystem being created, aimed at developing innovative dynamics,

- assessment of the level and capacity of self-developing innovation ecosystems,

- development of antitrust policy tools for platform ecosystems,

- self-analysis of economic entities, assessment of their place in ecosystems.

The study was carried out with the financial support of the Russian Foundation for Basic Research in the framework of scientific project No. 20-010-00333.

\section{References}

1. 1 M. Talmar, B. Walrave, K.S.Podoynitsyna, J. Holmström, A.G.L. Romme, Long Range Planning, 53,4 (2020)

2. 2 S.M. Lee, S. Trimi, Journal of Business Research, 123 (2021)

3. 3 J. F. Moore, Harvard Business Review, May/June (1993)

4. 4 G.B. Klejner, Jekonomicheskoe vozrozhdenie Rossii, 1 (59) (2019)

5. 5 L.A. Ramenskaja, Upravlenec, 11, 4 (2020).

6. 6 M.V. Alikaeva, L.O. Aslanova, A.A. Shinahov Proceedings of VSUET, 82, 3 (2020).

7. 7 D.Ju. Brjuhanov, C. Fan, G. Van, Schumpeterian Readings, The Ninth International Scientific Research Conference Proceedings, 3647 (2020)

8. 8 A.I. Tatarkin, Jekonomika regiona, 4 (36) (2013)

9. 9 D.A. Sevostyanov, Inverse analysis in management, Novosibirsk, IC NGAU "Zolotoy kolos" (2017)

10. 10 G. Kleiner, V. Karpinskaya. Transition of Firms from the Traditional to Ecosystem Form of Business: The Factor of Transaction Costs, CRFMELD 2019, LNNS 110 (2020)

11. 11 R.J. Rabelo et al., IFAC-PapersOnLine 48-3 (2015)

12. 12 J.A. Schumpeter, Theory of economic development. Capitalism, socialism and democracy, Moscow, Eksmo (in russ.) (2008)

13. 13 E.V. Popov, K.A. Semjachkov, V.L. Simonova, Journal of economic theory, 1 (2017)

14. $14 \mathrm{~J} . \mathrm{S}$

al., Environ. Res. Lett, 14093003 (2019)

15. 15 G.B. Klejner, S.E. Shhepetova, G.A. Shherbakov, Economics of Contemporary Russia, 4 (79) (2017)

16. 16 E.V. Popov, V.L. Simonova, I.P. Chelak, Innovations, 6 (260) (2020)

17. 17 S.Y. Barykin et al., J. Open Innov. Technol., 6, 124 (2020)

18. 18 O. E. Williamson, The economic institutions of capitalism: firms, markets, relational contracting, NY, Free press (1985)
19. 19 A. Shastitko, Voprosy Ekonomiki, 8 (2016)

20. 20 O. Granstrand, M. Holgersson, Technovation, 90-91 (2020)

21. 21 A.A. Panova, Economic policy, 13, 4 (2018) 